\title{
Cross-Cultural Counseling and the Near-Death Experience: Some Elaborations
}

Bette G. Furn, Ph.D.

Counseling Services, University of Hartford

The published literature on therapeutic models for aiding near-death experiencers (NDErs) has been sparse to date, and limited largely to a collection of practical and pragmatic techniques (Chapters 15-18 in Greyson \& Flynn, 1984; Greyson \& Harris, 1987). Those techniques and guidelines have proven useful. What has been lacking is a broad conceptual framework, or meta-model, through which to organize a diverse set of methods and to draw upon the skills of a wide range of professionals. The area of cross-cultural counseling and world views has been proposed to address that shortcoming.

The conceptual model I offered (Furn, 1987) reflects one attempt to explicate a framework in a field where none yet exists. I do not intend to prove its correctness, or to argue for its superiority over competing viewpoints. However, in the absence of comprehensive alternatives, the cross-cultural model may be considered first in a field of one. Nonetheless, critiques of that position have raised interesting and valuable issues that I will now address. In general, criticisms of the cross-cultural model tend to focus on one or both of the following: 1. the tenets of cross-cultural counseling and the merits of applying them to the NDE, and 2. the concept of adjustment and its pejorative connotations.

\section{Some Cross-Cultural Issues}

A major premise in the cross-cultural model (Furn, 1987) is that most mental health practitioners have the necessary skills to help NDErs.

Requests for reprints should be sent to Dr. Furn at the Counseling Services, University of Hartford, West Hartford, CT 06117. 
At least two clarifications need to be offered. First, it should be emphasized that while these skills represent what may be considered "necessary," i.e., meeting some minimum requirement, they are not presumed, in all circumstances, to be "sufficient." Second, there exists a distinction between skills and values. Professional skills may be acquired through training. The acquisition of values is a decidedly more gradual process, leading one to a general conception of the way things are, or to one's world view. A practitioner who has suitable skills does not necessarily have a world view compatible enough to work with a particular subgroup, or any individual member of that group.

A second premise of the cross-cultural model is the importance of acknowledging world views as a primary variable in any therapeutic interaction. A world view may be defined as how one perceives his or her relationship to the world, i.e., nature, institutions, other people, things, etc. (Sue, 1978a), or as a general conception of one's place in the universe (Horner \& Vandersluis, 1981). It is presumed that all people function within a culturally determined world view (Ibrahim \& Arredondo, 1986). Effective counseling, then, requires making overt both the counselor's and the client's world views (Ibrahim, 1985a, 1985b). To argue for the exclusive use of any one theoretical orientation, without taking the world views of the participants into account, not only may be a disservice to the client but also may raise ethical considerations (Ibrahim \& Arrendo, 1986). The phenomenological approach, humanistically and interpersonally sensitive though it may be, can leave the world view of the therapist as an "unknown" variable. The assumption is made that the world view of the therapist does not impinge upon his or her ability to empathize with the client, or influence the decisionmaking process of the client. That may be a major, and capricious, assumption. Culturally effective counselors are aware of their own values and assumptions regarding human behavior, consider the generic features of counseling that transcend particular schools of thought, and are eclectic (Sue, 1978b).

Finally, it seems necessary to re-emphasize that within this framework, the therapeutic encounter is assumed to occur between individuals who are valued equally. Treatment plans and diagnostic procedures are de-emphasized and a more collaborative alternative is proposed. Consider the position expressed by Farah Ibrahim (1985a):

If counselors and psychotherapists insist on analyzing and examining clients, they are persisting in setting up barriers by creating an unequal situation. Counseling (learning) relationships would be greatly 
enhanced if each counselor (facilitator) considered the client as a cultural equal and set about establishing a "relationship" between two equivalent beings. (p. 635)

\section{The Question of Adjustment}

It is unclear whether critics of this framework perceive an inconsistency between valuing a client while simultaneously recognizing that the client may be experiencing difficulties. The NDEr is in many ways atypical but should not be considered diseased simply by virtue of having had an NDE; on the other hand, there is no evidence through which to presume that such an individual is "immune." According to Kenneth Ring (1984), "some difficulties in readjusting are the rule, not the exception" (p. 92), if only as components of a transitory process. To date, these generally have seemed obscured by the more obviously growthinducing, revelatory aspects. The fact is that problems occur, regardless of how they are conceptualized or ultimately resolved.

It is clear that the term "adjustment" is objectionable, and perhaps reasonably so. However, some of the concern may be a function of at least two erroneous assumptions. First, that within the notion of "personenvironment fit," the onus of the responsibility for change is exclusively on the person. That is the traditional perspective (Ivey, 1981). It may also be the path of least resistance, and, therefore, more tempting to pursue. Interaction between the person and the environment is not linear, but mutual. The cross-cultural model, while aiding the experiencer, does not negate a responsibility to intervene also in the environment, or deny that the environment, inherently, is being altered. Second, the use of the term "adjustment" does not necessarily imply an "adjustment disorder" in the clinical or diagnostic sense. I hope the latter misconception has been sufficiently put to rest.

Perhaps it would be preferable to refer to the NDE and post-NDE as a process of coping, rather than adjusting. In either case, the controversy over the use of any label is likely to continue. In subsequent dialogues, it may be useful to recall that the NDE and its ramifications are not limited to NDErs. Others are affected as well, albeit not in the same manner, or to the same extent. The cross-cultural model can allow for a greater understanding of differences in world views, between NDEr and non-NDEr, and among NDErs. A model that allows for an understanding and exchange of world views can provide a forum for the education and enhancement of us all. 


\section{References}

Furn, B. (1987). Adjustment and the near-death experience: A conceptual and therapeutic model. Journal of Near-Death Studies, 6.

Greyson, B., \& Flynn, C. (Eds.). (1984). The near-death experience: Problems, prospects, perspectives. Springfield IL: Charles C Thomas.

Greyson, B., \& Harris, B. (1987). Clinical approaches to the near-death experiencer. Journal of Near-Death Studies, 6.

Horner, D., \& Vandersluis, E. (Eds.). (1981). Cross-cultural counseling, In G. Althen (Ed.), Learning across cultures. Washington, DC: National Association of Foreign Student Affairs.

Ibrahim, F. (1985a). Effective cross-cultural counseling and psychotherapy: A framework. Counseling Psychologist, 13, 625-638.

Ibrahim, F. (1985b). Effectiveness in cross-cultural counseling and psychotherapy: A framework. Psychotherapy, 22, 321-323.

Ibrahim, F., \& Arredondo, P. (1986). Ethical standards for cross-cultural counseling: Counselor preparation, practice, assessment, and research. Journal of Counseling and Development, 64, 349-352.

Ivey, A. (1981). Counseling and psychotherapy: Toward a new perspective. In A. J. Marsella \& P. B. Pedersen (Eds.), Cross-cultural counseling and psychotherapy. New York, NY: Pergamon Press.

Ring, K. (1984). Heading toward Omega. New York, NY: William Morrow.

Sue, D. (1978a). Eliminating cultural oppression in counseling: Toward a general theory. Journal of Counseling Psychology, 25, 419-428.

Sue, D. (1978b). Counseling across cultures. Personnel and Guidance Journal, 56, 451-462. 